Matematikai Közlemények

IV. kötet, 2016

doi:10.20312/dim.2016.06

\title{
A síkbeli projektív transzformáció matematikai modelljei
}

\author{
Závoti József \\ NyME, KTK, Közgazdasági és Módszertani Intézet \\ zavoti.jozsef@ktk.nyme.hu
}

\begin{abstract}
Összefoglaló. Ez a cikk a 2D projektív transzformáció paramétereinek a becslését tárgyalja $L_{1}$ normában és az iteráció során újrasúlyozott legkisebb négyzetek módszereivel.A transzformációs egyenletek két sík analitikus egymásra illesztését írják le. Emellett, a projektív transzformáció funkcionális modellt szolgáltat sík területek aerotriangulációs feladatának megoldásához is.
\end{abstract}

\begin{abstract}
This paper deals with the estimation of coefficients of the two dimensional projective transformation using the $L_{1}$-norm and the iteratively reweighted least squares methods. The equations of this transformation express the analytical rectification from one plane to another. In addition, the projective transformation can be the functional model solving aerotriangulation problem on flat terrains.
\end{abstract}

\section{Bevezetés}

A tér síkra történő leképezése gyakran előforduló feladat (például a számítógépes grafika, vagy a festészet). A fényképezés során a tárgyakhoz, azoknak minden egyes pontjához egyértelmüen hozzárendeljük a keletkezett kép bizonyos pontjait. Ezt a megfeleltetést ponttranszformációnak nevezzük. Egyes esetekben a vetített képen a tárgy bizonyos deformációkat szenvedhet, mint például a projektív transzformáció esetében is. A digitális kamerák digitalizált képeit projektív transzformációval köthetjük össze.

\section{A 2D projektív transzformáció allapegyenletei}

Két sík centrális projekciójának alapösszefüggéseit a jólismert törtlineáris egyenletekkel adhatjuk meg [1] és [3]:

$$
X=\frac{a_{1} x+a_{2} y+a_{3}}{c_{1} x+c_{2} y+1}, \quad Y=\frac{b_{1} x+b_{2} y+b_{3}}{c_{1} x+c_{2} y+1},
$$

ahol $(x, y)^{T}$ a képpont koordinátái,

$(X, Y)^{T}$ a tárgypont koordinátái,

$\mathbf{q}^{T}=\left(a_{1}, a_{2}, a_{3}, b_{1}, b_{2}, b_{3}, c_{1}, c_{2}\right)^{T}$ ismeretlen paraméterek.

A nyolc független ismeretlen paraméter meghatározásához legalább négy nem kollineáris pontpárra van szükség. Négynél több adott pontpár esetén kiegyenlítéssel határozhatjuk meg az ismeretleneket. Az ismeretlen paraméterek meghatározása után az (1) egyenletek használhatók tetszőleges, a képkoordináta-rendszerben megadott pontnak a tárgykoordináta-rendszerbe való transzformációjához. 


\section{Projektív transzformáció paramétereinek becslése $L_{1}$-normában}

Az (1) egyenletrendszer nevezőjével való átszorzás, és az egyenletek rendezése után a mérési eredményekre az alábbi javítási egyenletek írhatók fel :

$$
\begin{gathered}
v_{x_{i}}=-a_{1} x_{i}-a_{2} y_{i}-a_{3}+c_{1} x_{i} X_{i}+c_{2} y_{i} X_{i}+X_{i} \\
v_{y_{i}}=-b_{1} x_{i}-b_{2} y_{i}-b_{3}+c_{1} x_{i} Y_{i}+c_{2} y_{i} Y_{i}+Y_{i} \\
i=1,2, \ldots, n
\end{gathered}
$$

ahol $n \geq 4$ a mindkét rendszerben adott közös pontok száma.

$L_{1}$ - normában az ellentmondásokat a következőképp definiáljuk:

$$
\rho_{i}=\sqrt{v_{x_{i}}^{2}+v_{y_{i}}^{2}} \geq 0, \quad i=1,2, \ldots, n
$$

Célunk megkeresni az alábbi célfüggvény minimumát:

$$
f(\mathbf{q})=\sum_{i=1}^{n} \rho_{i}
$$

Helyettesítsük (3) összefüggést az alábbi egyenlőtlenséggel:

$$
\sqrt{v_{x_{i}}^{2}+v_{y_{i}}^{2}} \leq \rho_{i}
$$

Az (5) formula megengedi, hogy a transzformált pont vagy a $\rho_{i}$ sugarú kör belsejében, vagy a kör határán helyezkedjék el.

A (3), (4) és (5) összefüggések egy nemlineáris optimalizálási feladatot definiálnak. Ezt a nemlineáris optimalizálási feladatot a Fuchs [2] által bevezetett módszerrel linearizáljuk.

A $\left(v_{x_{i}}, v_{y_{i}}\right)$ ellentmondás vektorokat írjuk fel polár-koordinátákkal:

$$
v_{x_{i}}=\rho_{i} \cos \tau_{i} \quad v_{y_{i}}=\rho_{i} \sin \tau_{i} .
$$

Ekkor tetszőleges $\lambda(0 \leq \lambda \leq 2 \pi)$ esetén igazak a következő összefüggések:

$$
\begin{aligned}
& v_{x_{i}} \cos \lambda=\rho_{i} \cos \tau_{i} \cos \lambda \\
& v_{y_{i}} \sin \lambda=\rho_{i} \sin \tau_{i} \sin \lambda .
\end{aligned} .
$$

A (7) képletben szereplö egyenleteket összeadva kapjuk:

$$
\begin{gathered}
v_{x_{i}} \cos \lambda+v_{y_{i}} \sin \lambda=\rho_{i} \cos \left(\tau_{i}-\lambda\right) \leq \rho_{i}, \\
0 \leq \lambda \leq 2 \pi .
\end{gathered}
$$

A fentiek szerint az (5) összefüggés helyettesíthető végtelen sok $(\lambda \in[0,2 \pi])$ egyenlőtlenséggel:

$$
\begin{gathered}
-a_{1} x_{i} \cos \lambda-a_{2} y_{i} \cos \lambda-a_{3} \cos \lambda+c_{1} x_{i} X_{i} \cos \lambda+c_{2} y_{i} X_{i} \cos \lambda+X_{i} \cos \lambda+ \\
-b_{1} x_{i} \sin \lambda-b_{2} y_{i} \sin \lambda-b_{3} \sin \lambda+c_{1} x_{i} Y_{i} \sin \lambda+c_{2} y_{i} Y_{i} \sin \lambda+Y_{i} \sin \lambda \leq \rho_{i} \\
i=1,2, \ldots, n, \quad 0 \leq \lambda<2 \pi .
\end{gathered}
$$


Válasszunk minden pontra csak véges sok $\lambda_{i j}\left(j=1,2, \ldots, m_{i}\right)$ értéket. Geometriailag ez azt jelenti, hogy a kört egy $m_{i}$ oldalú poligonnal közelítjük. Ekkor az eredeti nemlineáris optimalizálási feladatunk a következő lineáris programozási feladatba megy át:

$$
\begin{gathered}
-a_{1} x_{i} \cos \lambda_{i j}-b_{1} x_{i} \sin \lambda_{i j}-a_{2} y_{i} \cos \lambda_{i j}-b_{2} y_{i} \sin \lambda_{i j}-a_{3} \cos \lambda_{i j}-b_{3} \sin \lambda_{i j} \\
+c_{1}\left(x_{i} X_{i} \cos \lambda_{i j}+x_{i} Y_{i} \sin \lambda_{i j}\right)+c_{2}\left(y_{i} X_{i} \cos \lambda_{i j}+y_{i} Y_{i} \sin \lambda_{i j}\right)-\rho_{i} \leq-X_{i} \cos \lambda_{i j}-Y_{i} \sin \lambda_{i j} \\
\sum \rho_{i} \rightarrow \min \quad \rho_{i} \geq 0 \\
i=1,2, \ldots, n
\end{gathered}
$$

Az előbbi lineáris programozási feladat az eredeti nemlineáris optimalizálási feladatot approximálja. Ha a (10) formulákkal átdefiniált modellt primál lineáris optimalizálási feladatnak tekintjük, akkor a hozzátartozó duál problémát is megadhatjuk, amelynek a megoldása után kapjuk a primál, az eredeti feladat megoldását.

\section{A síkbeli projektív transzformáció iterációs becslései}

\subsection{Hagyományos kiegyenlítési modell}

Az (1) formulák közös nevezőjével történő átszorzás, valamint az egyenletek rendezése után kapjuk:

$$
\begin{gathered}
-X=-a_{1} x-a_{2} y-a_{3}+c_{1} x X+c_{2} y X \\
-Y=-b_{1} x-b_{2} y-b_{3}+c_{1} x Y+c_{2} y Y
\end{gathered}
$$

A síkbeli projektív transzformáció hagyományos kiegyenlítési modelljében a tárgykoordináták kapják a javításokat. Mátrix formában a javítási egyenletek így adhatók meg:

$$
\left(\begin{array}{cccccccc}
-x_{1} & 0 & -y_{1} & 0 & -1 & 0 & x_{1} X_{1} & y_{1} X_{1} \\
0 & -x_{1} & 0 & -y_{1} & 0 & -1 & x_{1} Y_{1} & y_{1} Y_{1} \\
-x_{2} & 0 & -y_{2} & 0 & -1 & 0 & x_{2} X_{2} & y_{2} X_{2} \\
0 & -x_{2} & 0 & -y_{2} & 0 & -1 & x_{2} Y_{2} & y_{2} Y_{2} \\
\vdots & & & & & & & \\
-x_{n} & 0 & -y_{n} & 0 & -1 & 0 & x_{n} X_{n} & y_{n} X_{n} \\
0 & -x_{n} & 0 & -y_{n} & 0 & -1 & x_{n} Y_{n} & y_{n} Y_{n}
\end{array}\right)\left(\begin{array}{c}
a_{1} \\
b_{1} \\
a_{2} \\
b_{2} \\
a_{3} \\
b_{3} \\
c_{1} \\
c_{2}
\end{array}\right)=\left(\begin{array}{c}
-X_{1} \\
-Y_{1} \\
-X_{2} \\
-Y_{2} \\
\vdots \\
-X_{n} \\
-Y_{n}
\end{array}\right)+\left(\begin{array}{c}
v_{x_{1}} \\
v_{y_{1}} \\
v_{x_{2}} \\
v_{y_{2}} \\
\vdots \\
v_{x_{n}} \\
v_{y_{n}}
\end{array}\right) .
$$

$\operatorname{Az}\left(X_{i}, Y_{i}\right) i=1,2, \ldots, n$ pontokhoz rendelt súlyokat jelölje $\left(p_{x_{i}}, p_{y_{i}}\right)$.

Ekkor a fenti kiegyenlítőszámítási modell normál mátrixa a következőképpen adható meg:

$\left(\begin{array}{cccccccc}\sum p_{x_{i}} x_{i}^{2} & 0 & \sum p_{x_{i}} x_{i} y_{i} & 0 & \sum p_{x_{i}} x_{i} & 0 & -\sum p_{x_{i}} x_{i} X_{i} & -\sum p_{x_{i}} x_{i} y_{i} X_{i} \\ 0 & \sum p_{y_{i}} x_{i}^{2} & 0 & \sum p_{y_{i}} x_{i} y_{i} & 0 & \sum p_{y_{i}} x_{i} & -\sum p_{y_{i}} x_{i} Y_{i} & -\sum p_{y_{i}} x_{i} y_{i} Y_{i} \\ \sum p_{x_{i}} x_{i} y_{i} & 0 & \sum p_{x_{i}} y_{i}^{2} & 0 & \sum p_{x_{i}} y_{i} & 0 & -\sum p_{x_{i}} x_{i} y_{i} X_{i} & -\sum p_{x_{i}} y_{i}^{2} X_{i} \\ 0 & \sum p_{y_{i}} x_{i} y_{i} & 0 & \sum p_{y_{i}} y_{i}^{2} & 0 & \sum p_{y_{i}} y_{i} & -\sum p_{y_{i}} x_{i} y_{i} Y_{i} & -\sum p_{y_{i}} y_{i}^{2} Y_{i} \\ \sum p_{x_{i}} x_{i} & 0 & \sum p_{x_{i}} y_{i} & 0 & n & 0 & -\sum p_{x_{i}} x_{i} X_{i} & -\sum p_{x_{i}} y_{i} X_{i} \\ 0 & \sum p_{y_{i}} x_{i} & 0 & \sum p_{y_{i}} y_{i} & 0 & n & -\sum p_{y_{i}} x_{i} Y_{i} & -\sum p_{y_{i}} y_{i} Y_{i} \\ -\sum p_{x_{i}} x_{i}^{2} X_{i} & -\sum p_{x_{i}} x_{i}^{2} Y_{i} & -\sum p_{x_{i}} x_{i} y_{i} X_{i} & -\sum p_{x_{i}} x_{i} y_{i} Y_{i} & -\sum p_{x_{i}} x_{i} X_{i} & -\sum p_{x_{i}} x_{i} Y_{i} & \sum p_{x_{i}} x_{i}^{2}\left(X_{i}^{2}+Y_{i}^{2}\right) & \left.\sum p_{x_{i}} x_{i} y_{i} X_{i}^{2}+Y_{i}^{2}\right) \\ -\sum p_{y_{i}} x_{i} y_{i} X_{i} & -\sum p_{y_{i}} x_{i} y_{i} Y_{i} & -\sum p_{y_{i}} y_{i}^{2} X_{i} & -\sum p_{y_{i}} y_{i}^{2} Y_{i} & -\sum p_{y_{i}} y_{i} X_{i} & -\sum p_{y_{i}} y_{i} Y_{i} & \sum p_{y_{i}} x_{i} y_{i}\left(X_{i}\left(X_{i}^{2}+Y_{i}^{2}\right)\right. & \sum p_{y_{i}} y_{i}^{2}\left(X_{i}^{2}+Y_{i}^{2}\right)\end{array}\right)$


A normál vektor az alábbi alakot veszi fel:

$$
\left(-\sum p_{x_{i}} x_{i} X_{i},-\sum p_{z_{i}} x_{i} Y_{i},-\sum p_{x_{i}} y_{i} X_{i},-\sum p_{y_{i}} y_{i} Y_{i},-\sum p_{x_{i}} X_{i},-\sum p_{y_{i}} Y_{i},-\sum p_{x_{i}} x_{i}\left(X_{i}^{2}+Y_{i}^{2}\right),-\sum p_{y_{i}} y_{i}\left(X_{i}^{2}+Y_{i}^{2}\right)\right)^{T}
$$

Az első lépésben a $p_{x_{i}}=1$ és $p_{y_{i}}=1 \quad(i=1,2, \ldots, n)$ súlyokkal elvégzünk egy hagyományos kiegyenlítést, majd választunk egy maximum likelihood típusú becslést és a kapott javítások alapján a választott módszer súlyfüggvénye felhasználásával új súlyok határozhatók meg. Az iterációt addig folytatjuk, amíg a konvergencia egy adott határt elér.

Részletek a [5] szakirodalomban találhatók.

\subsection{Percy Tham féle modell}

A síkbeli projektív transzformáció Percy Tham [7] féle modelljében a képkoordinátákról tételezzük fel, hogy hibákkal terheltek. Legyen

$$
s_{x}=a_{1}^{0} x+a_{2}^{0} y+a_{3}^{0} \quad s_{y}=b_{1}^{0} x+b_{2}^{0} y+b_{3}^{0} \quad \theta=c_{1}^{0} x+c_{2}^{0} y+1 .
$$

A kezdőértékeket megadhatjuk a hagyományos modell első iterációjából származó értékekkel.

Az $X\left(a_{1}, a_{2}, a_{3}, c_{1}, c_{2}\right)$ és $Y\left(b_{1}, b_{2}, b_{3}, c_{1}, c_{2}\right)$ függvények lineárisan közelíthetők a többváltozós függvények Taylor sora szerinti sorfejtés alapján:

$$
\begin{aligned}
& X=\frac{s_{x}}{\theta}+\frac{x d a_{1}}{\theta}+\frac{y d a_{2}}{\theta}+\frac{d a_{3}}{\theta}-\frac{s_{x} x d c_{1}}{\theta^{2}}-\frac{s_{x} y d c_{2}}{\theta^{2}} \\
& Y=\frac{s_{y}}{\theta}+\frac{x d b_{1}}{\theta}+\frac{y d b_{2}}{\theta}+\frac{d b_{3}}{\theta}-\frac{s_{y} x d c_{1}}{\theta^{2}}-\frac{s_{y} y d c_{2}}{\theta^{2}}
\end{aligned}
$$

A fenti egyenletekből a síkbeli projektív transzformáció Percy Tham féle közvetítő egyenleteire a következő kifejezéseket kapjuk:

$$
\begin{aligned}
& s_{x}-\theta X=-x d a_{1}-y d a_{2}-d a_{3}+\frac{s_{x} x}{\theta} d c_{1}+\frac{s_{x} y}{\theta} d c_{2} \\
& s_{y}-\theta Y=-x d b_{1}-y d b_{2}-d b_{3}+\frac{s_{y} x}{\theta} d c_{1}+\frac{s_{y} y}{\theta} d c_{2}
\end{aligned}
$$

Általánosan a Percy Tham féle modell közvetítő egyenleteinek mátrixa a következőképpen adható meg:

$$
\left(\begin{array}{ccccccccc}
-x_{1} & 0 & -y_{1} & 0 & -1 & 0 & x_{1} \frac{s_{x}}{\theta} & y_{1} \frac{s_{x}}{\theta} \\
0 & -x_{1} & 0 & -y_{1} & 0 & -1 & x_{1} \frac{s_{y}}{\theta} & y_{1} \frac{s_{y}}{\theta} \\
-x_{2} & 0 & -y_{2} & 0 & -1 & 0 & x_{2} \frac{s_{x}}{\theta} & y_{2} \frac{s_{x}}{\theta} \\
0 & -x_{2} & 0 & -y_{2} & 0 & -1 & x_{2} \frac{s_{y}}{\theta} & y_{2} \frac{s_{y}}{\theta} \\
\vdots & & & & & & & \\
0 & -x_{n} & 0 & -y_{n} & 0 & -1 & x_{n} \frac{s_{y}}{\theta} & x_{n} \frac{s_{y}}{\theta}
\end{array}\right)
$$

Vezessük be a következő jelöléseket:

$$
\begin{aligned}
d X_{i} & =s_{x}-\theta X_{i} \\
d Y_{i} & =s_{y}-\theta Y_{i}
\end{aligned}
$$


Ebben az esetben a normál vektor a következő formában adódik:

$$
\left(-\sum x_{i} d X_{i,}-\sum x_{i} d Y_{i},-\sum y_{i} d X_{i},-\sum y_{i} d Y_{i},-\sum d X_{i},-\sum d Y_{i}, \sum x_{i}\left(s_{x} X_{i}+s_{y} Y_{i}\right), \sum y_{i}\left(s_{x} X_{i}+s_{y} Y_{i}\right)\right)^{T} .
$$

A projektív transzformáció Percy Tham -féle módszerének robusztus becslési modelljét úgy kapjuk, hogy a (17) közvetítő egyenletekhez súlyokat rendelünk - első lépésben $p_{x_{i}}=1 ; \quad p_{y_{i}}=1 \quad(i=1,2, \ldots, n)$ - és ezen súlyok felhasználásával végezzük el a kiegyenlítést. A további lépésekben a 4.1 alfejezetben ismertetett iteratív becslési algoritmus szerint hajtjuk végre a számításokat.

\subsection{Tárczy - Hornoch féle modell}

A Tárczy-Hornoch [6] féle modellben a képkoordinátákat tekintjük véletlen hibával terheltnek, és a kiegyenlítés során a képkoordinátákhoz rendelünk a javításokat:

$$
X=\frac{a_{1}\left(x+v_{x}\right)+a_{2}\left(y+v_{x}\right)+a_{3}}{c_{1}\left(x+v_{x}\right)+c_{2}\left(y+v_{y}\right)+1} \quad Y=\frac{b_{1}\left(x+v_{x}\right)+b_{2}\left(y+v_{x}\right)+b_{3}}{c_{1}\left(x+v_{x}\right)+c_{2}\left(y+v_{y}\right)+1}
$$

A keresett ismeretlenekre vezessük be az $a_{1}^{0}, a_{2}^{0}, a_{3}^{0}, b_{1}^{0}, b_{2}^{0}, b_{3}^{0}, c_{1}^{0}$ és $\mathrm{c}_{2}^{0}$ közelítő értékeket, amelyeket kaphatunk például a hagyományos kiegyenlítésből.

Az $X\left(a_{1}, a_{2}, a_{3}, c_{1}, c_{2}\right)$ és $Y\left(b_{1}, b_{2}, b_{3}, c_{1}, c_{2}\right)$ függvények Taylor sorfejtésében hanyagoljuk el a másod- és magasabb rendü tagokat, ekkor a (21) összefüggésekböl kapott javítási egyenletek a következő alakot veszik fel:

$$
\begin{gathered}
s_{x}-x X c_{1}^{0}+y X c_{2}^{0}-X=\left(X c_{1}^{0}-a_{1}^{0}\right) v_{x}+\left(X c_{2}^{0}-a_{2}^{0}\right) v_{y}-x d a_{1}-y d a_{2}-d a_{3}+x X d c_{1}+y X d c_{2} \\
s_{y}-x Y c_{1}^{0}+y Y c_{2}^{0}-Y=\left(Y c_{1}^{0}-b_{1}^{0}\right) v_{x}+\left(Y c_{2}^{0}-b_{2}^{0}\right) v_{y}-x d b_{1}-y d b_{2}-d b_{3}+x Y d c_{1}+y Y d c_{2}
\end{gathered}
$$

A fenti egyenleteket valamennyi közös illesztőpontra felírhatjuk:

$$
\begin{gathered}
R_{1} v_{1}+A_{1} q=b_{1} \\
R_{2} v_{2}+A_{2} q=b_{2} \\
\vdots \\
R_{n} v_{n}+A_{n} q=b_{n}
\end{gathered}
$$

vagy

$$
\left[\begin{array}{cccc}
\boldsymbol{R}_{1} & 0 & 0 & 0 \\
0 & \boldsymbol{R}_{2} & & \\
& & \ddots & \\
0 & 0 & 0 & \boldsymbol{R}_{n}
\end{array}\right]\left[\begin{array}{c}
\boldsymbol{v}_{\boldsymbol{1}} \\
\boldsymbol{v}_{2} \\
\vdots \\
\boldsymbol{v}_{n}
\end{array}\right]+\left[\begin{array}{c}
A_{1} \\
A_{2} \\
\vdots \\
A_{n}
\end{array}\right] q=\left[\begin{array}{c}
b_{1} \\
b_{2} \\
\vdots \\
b_{n}
\end{array}\right],
$$

ahol $\boldsymbol{q}^{T}=\left(a_{1}, b_{1}, a_{2}, b_{2}, a_{3}, b_{3}, c_{1}, c_{2}\right)$ ismeretlen vektor.

$$
\begin{aligned}
\boldsymbol{b}_{\boldsymbol{i}} & =\left(\begin{array}{l}
s_{x_{i}}-x_{i} X_{i} c_{1}^{0}+y_{i} X_{i} c_{2}^{0}-X_{i} \\
s_{y_{i}}-x_{i} Y_{i} c_{1}^{0}+y_{i} Y_{i} c_{2}^{0}-Y_{i}
\end{array}\right) \\
\boldsymbol{R}_{\boldsymbol{i}} & =\left(\begin{array}{c}
X_{i} c_{1}^{0}-a_{1}^{0} X_{i} c_{2}^{0}-a_{2}^{0} \\
Y_{i} c_{1}^{0}-b_{1}^{0} Y_{i} c_{2}^{0}-b_{2}^{0}
\end{array}\right) \\
\boldsymbol{A}_{\boldsymbol{i}} & =\left(\begin{array}{cccccccc}
-x_{i} & 0 & -y_{i} & 0 & -1 & 0 & x_{i} X_{i} & y_{i} X_{i} \\
0 & -x_{i} & 0 & -y_{i} & 0 & -1 & x_{i} Y_{i} & y_{i} Y_{i}
\end{array}\right) .
\end{aligned}
$$


A feladat hipermatrixos alakja:

$$
R \boldsymbol{v}+A q=b
$$

$\mathrm{Az}\left(x_{i}, y_{i}\right) \quad(i=1,2, \ldots, n)$ pontokhoz rendelt súlyokat jelölje $\left(p_{x_{i}}, p_{y_{i}}\right)$.

Ezen súlyokat az első lépésben egységnyinek választjuk. A további iterációs lépések során a súlyok értékének megállapítása a 4.1 és 4.2 alfejezetben tárgyalt robusztus becslési módszerek adott súlyfüggvényei alapján történik. alapján:

A (26) összefüggésben szereplő kiegyenlítőszámítási modell megoldása Mikhail [4]

$$
q=\left(A^{T}\left(R_{Q} Q R^{T}\right)^{-1} A\right)^{-1} A^{T}\left(R Q R^{T}\right)^{-1} b
$$

ahol $\boldsymbol{Q}$ a $p_{x_{i}}$ és $p_{y_{i}}$ súlyok felhasználásával adódó kofactor matrix.

A megoldási algoritmust új súlyok bevezetésével addig ismételjük, amíg az egymás utáni lépésekben számolt javítások az általunk választott stabilitási kritériumnak megfelelnek.

\section{5. Összefoglalás}

A tanulmányban a sík projektív transzformációjára adtunk meg matematikai modelleket.

Tárgyaltuk a leképezés paramétereinek becslését $L_{1}$ normában, amelyben az eredetileg nemlineáris problémát lineáris programozási feladatra vezettük vissza. Levezettuik a projektív transzformáció hagyományos modelljének normál egyenletét. A Percy Tham féle modellnek általánosan megadtuk az iteráció során újrasúlyozott legkisebb négyzetek módszerével előállítható megoldását. A Tárczy-Hornoch féle kiegyenlítőszámítási modellt hipermátrixok felhasználásával oldottuk meg. A [8] szakirodalom a projektív transzformáció numerikus megoldására is további támpontokat nyújt.

\section{Irodalomjegyzék:}

[1] Brandstätter, G.: Sitzungsberichte Abt. II, Wien, (1996), 57-109.

[2] Fuchs, H.: Manuscr. Geod. 7, (1982),151-207.

[3] Gruber, O.: Ferienkurs in Photogrammetrie. Stuttgart, Verlag Konrad Wittwer, 1930.

[4] Mikhail, E. M.: Observations and Least Squares. New York, Harper \& Row, 1976.

[5] Somogyi, J., Závoti, J.: Acta Geod. Geoph. Mont. Hung., (1993), 413-420.

[6] Tárczy-Hornoch A.: Mitteilungen der berg- und hüttenmännischen Abteilungan der kgl. ung. P.J. Uni. Band XIII, 1941.

[7] Tham, P.: Photogrammetrische Auswertung ebenerge Gelände. Stockholm, Centraltryckeriet Esselte Aktiebolag, 1939.

[8] Somogyi, J., Závoti, J.: Acta Geod. Geoph. Hung., (1998), 279-288. 